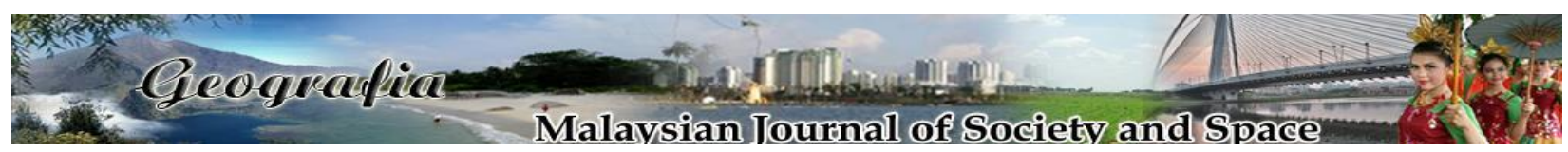

\title{
Urban sprawl literature review: Definition and driving force
}

\author{
Muhammad Yazrin Yasin ${ }^{1,2}$, Mariney Mohd Yusoff ${ }^{1}$, Jamalunlaili Abdullah², Nisfariza Mohd Noor ${ }^{1}$, \\ Norzailawati Mohd Noor ${ }^{3}$ \\ ${ }^{1}$ Department of Geography, University Malaya \\ ${ }^{2}$ Faculty of Architecture, Planning and Survey, University Technology MARA \\ ${ }^{3}$ Kuliyyah of Architecture and Environmental Design, International Islamic University Malaysia \\ Correspondence: Muhammad Yazrin Yasin (email: yazrinyasin@gmail.com)
}

Received: 07 July 2020; Accepted: 17 February 2021; Published: 29 May 2021

\begin{abstract}
The concept of urban sprawl spans multiple dimensions indicating how urban built-up land cover adds up throughout exurban landscapes. These different dimensions of urban sprawl require a reexamination of definitions and their driving forces because certain policies were formulated from the proposition of informed knowledge and have implicitly gratified urban sprawl into adjoining urban peripheries. This article aimed to offer an alternative perspective on urban sprawl, contributing to a better comprehension of its definition and driving forces. The revision of urban sprawl definitions into six categories have been done based on their repercussion, unaesthetic design, driving force, undesirable pattern, extended character, and their consequences to the environment, to assist in giving an in-depth understanding of urban sprawl in order to implicate effective policy actions. A revision of the driving forces of urban sprawl into various socioeconomic, institutional, demographic, market and technological factors further support the research on spatial planning and urban growth. It is conducted through a detailed discussion and analysis of evidence retrieved from wide-ranging urban studies literature. An informed decision through understanding the driving force of urban sprawl and addressing the root cause can produce a twofold benefit of socio-environment wellbeing and growth-friendly policy initiatives.
\end{abstract}

Keywords: Driving force, urban growth, urban sprawl, urban sprawl definition.

\section{Introduction}

Urban sprawl has become a general concern prior to sustainable development concepts being introduced. However, by adopting a sustainable development 'lifestyle', urban growth management creates sprawl that is worse than before (Horn, 2014). This is because the extensive challenge to acknowledge with urban sprawl is that the term has a different meaning in different disciplines. This article aims to truly differentiate aspects of sprawl from those aspects most people have misinterpreted. This article develops a conceptual framework for the phenomenon of urban 
sprawl, through a re-examination of the definitions and the driving forces of urban sprawl, retrieved and improved from previous studies of urban sprawl. The multidimensional definitions provide an in-depth discussion to implicate preferable policy action.

\section{Definition of urban sprawl}

There is very little mutual recognition either on the definition of urban sprawl or in the significance and/ or insignificance of the consequences. Galster et al. (2001) has composed six definitions categories of urban sprawl. Urban sprawl indicates a state of characterizing a whole or part of an urban area at a given time. It means urban sprawl is a developmental process that contributes changes to land use patterns, with a variety of shapes and sizes. Subsequently, Galster emphasized the pattern of land use to distinguish the condition from its causes and effects. Those specific dimensions used to distinguish the condition of land use were: density, proximity, continuity, centrality, clustering, mixed-use and nuclearity.

Table 1 suggests a re-examination of urban sprawl definitions largely available in academic literature, which would become useful comparisons of a state of affairs to define which circumstances had fewer or greater amounts of sprawl. The six definitions of urban sprawl were thoroughly constructed to include physical, morphological, causal, preferential, social and environmental aspects of urban environment and was modified from Galster et al. (2001).

Table 1. Re-examination of urban sprawl definitions.

\begin{tabular}{|c|c|c|}
\hline No. & Defined by & Description/ characteristics \\
\hline 1. & $\begin{array}{l}\text { Its repercussion of } \\
\text { uncontrolled growth }\end{array}$ & $\begin{array}{l}\text { Urban sprawl is the repercussion of the existence or the absence of development } \\
\text { policy such as zoning, urban growth boundary or development control. }\end{array}$ \\
\hline 2. & $\begin{array}{l}\text { Its unaesthetic and } \\
\text { injustice design }\end{array}$ & $\begin{array}{l}\text { Urban sprawl create clusters of homogenous design that produce unaesthetic or } \\
\text { unpleasant view, its ugly suburban monotonous housing cause by poor planning } \\
\text { or limited autonomy and cause social and economic injustice. }\end{array}$ \\
\hline 3. & Its driving forces & $\begin{array}{l}\text { Urban sprawl is the dispersion of residential and employment development, } \\
\text { industrial externalities, market forces and neighborhood incentives that push } \\
\text { development further away. }\end{array}$ \\
\hline 4. & $\begin{array}{l}\text { Its undesirable pattern } \\
\text { of growth }\end{array}$ & $\begin{array}{l}\text { Urban sprawl has a nasty pattern of development spreading further from the city } \\
\text { such as leapfrogging, ribbon, strip development and periphery areas. }\end{array}$ \\
\hline 5. & $\begin{array}{l}\text { Its expansion character } \\
\text { and excessive growth }\end{array}$ & $\begin{array}{l}\text { Urban sprawl expand excessively, with rapid urbanization and population } \\
\text { spread outside their periphery and into rural area, convert and create spatial } \\
\text { reorganization and functionality change. }\end{array}$ \\
\hline 6. & $\begin{array}{l}\text { Its consequences to } \\
\text { socio-environment }\end{array}$ & $\begin{array}{l}\text { Urban sprawl affects and changes its environment such as loss of productive } \\
\text { agricultural lands, lower accessibility and private transport dependency, } \\
\text { increase carbon emission and increase runoff water. }\end{array}$ \\
\hline
\end{tabular}

a. Defined by its repercussion of uncontrolled growth

Several instances of literature are definite that uncontrolled or unrestrained urban growth is largely blamed for the occurrence of urban sprawl. Hosseini and Hajilou (2019) refers to urban sprawl as an outgrowth of unrestrained urban growth, with consequences that are mostly present outside urban peripheries, alongside highways connecting other cities or satellite urban centers. Planners 
and planning authorities are to blame for incompetence in integrated policy planning and poor decision making. The repercussions are severe deficiencies of public utilities, infrastructure and amenities. Both Peiser (1984) and Dowling (2000) also viewed that urban sprawl is a result of uncontrolled growth. Peiser stated that urban sprawl becomes the dominant pattern of development. The absence of control in term of land use conversion and perimeter for environmentally fragile areas are among the evidence.

Peiser (2001) elaborated that the uncontrolled growth is related to: (i) rural and agricultural land use conversion done prematurely; (ii) urban land use with adjacent land use was poorly planned; and (iii) urban land use that was not proportionally developed with public facilities and services. Dowling (2000), in his research blamed failure of public policy that resorted to abrupt initiative design to curb urban sprawl. This failure lead to unnecessary increases in providing public infrastructures and amenities on top of shrinking central cities, prime farmland and environment. Pendall (1999) cited and reviewed the Nelson and Duncan (1995) broad definition of urban sprawl as unplanned, uncontrolled and uncoordinated single-use instead of mix-use development with various growth pattern of low density, scattered/ dispersed, leapfrog or isolated development. Pendall (1999) however disagreed and suggested that local authorities should let growth progress in its own way. He explained that federal and state level public policies already limited low-density development through tax incentives and fiscal mechanisms. Thus, urban growth boundaries and land use control at local levels would contradictorily promote urban sprawl to their periphery.

A study of urban sprawl analysis using remote sensing by Viana et al. (2019) argues urban sprawl is not only unplanned and uncontrolled urban development, but it is also regarded with negative connotations associated with complex resources depletion such as land, water, air and health. In other cases, urban sprawl is not a result of uncontrolled urban development, but a failure to comply with urban development policy. Feng et al. (2019) is determining the driving force of urban sprawl at the prefecture level in China. The study points out that a failure to comply with urban policy caused land growth rates to be higher than population growth rates. Nope et al. (2020) presents that the transit-oriented development (TOD) application model has benefitted from sprawled districts of Kupang City, Indonesia. The study agrees that uncontrolled urbanization also has positive effects on economy, culture, transportation and energy.

\section{b. Defined by its unaesthetic and injustice design}

In the context of urban sprawl defined by its unaesthetic design, urban sprawl is seen as a disorganized and unattractive expansion of an urban or industrial area into the adjoining countryside. Urban sprawl is visibly ugly as a result of homogenous form of development (Fulton, 1996; Gordon \& Richardson, 1997). Mills (1981) defined and critiques urban sprawl as aesthetically unattractive. Burchell et al. (1998) indicated how wealthy people decreased aesthetic appeal of suburban and exurban landscapes. Yu (2013) described the definition as illusive and urban sprawl as a judgmental term itself. This is due to the fact that urban sprawl is an aesthetic judgement on urban expansion and is associated with many undesirable accounts. Bruegmann (2015) narrates urban sprawl as economic inequality, social injustice, unaesthetic appearance and environmental degradation. He pointed out that economic, social, spiritual and environmental areas were negatively impacted and dampen by urban sprawl. The vicious consequences are hardpressed for self-improvement and are deemed as outcast from equal opportunity. 
$\mathrm{Wu}$ (2006) first described the aesthetic character of urban sprawl as ugly. Subsequently, Wu supplemented the urban sprawl definition with other destructive characters, damaging consequences and was responsible for several non-communicable diseases. Bhatta (2010) was concerned that urban sprawl can develop additional negative consequences in terms of aesthetic views such as monotonous and ugly suburban landscapes. Urban and rural landscapes should have a strong traditional and distinctive aesthetic value, but urban sprawl distorts it. Habibi and Asadi (2011) concurred with the above statement as they examined the past characteristics of cities and how the beginning of urban sprawl has changed glorified features that differentiate cities and rural areas. Cities once representing high civilization and culture, hence have complex-built environments, while rural area were destined to be tranquil and scenic. Salvia et al. (2019) study of sustainable land management has described that urban sprawl has caused uneven rural landscape changes.

\section{c. Defined by its driving forces}

Urban sprawl in early 1960s in the United States was largely driven by speculative land prices, land and property tax and market forces. (Clawson, 1962; Bahl, 1968). Early literature defined urban sprawl as a product of postwar suburbanization that was highly driven by speculation, taxes and market (Benites-Gambirazio, 2017; Franklin \& Plane 2019; Dibble et al., 2019). Large scale speculation has serious consequences for vacant and 'leap' land prices. The situation has formed a discontinuity in urban expansion thus created a leapfrog development. Decades after post war has seen the size and speed of urban sprawl escalate and the main driving forces of urban sprawl are much more diversified.

Guan et al. (2020) quantified the urban sprawl index of the Yangtze Economic Belt. The study defined urban sprawl as driven by economy, population and land. The result of the study has concluded that large economic development, rapid population growth, numerous suitable and available pieces of land have been identified as significance factors that contributed to the economic belt and are simultaneously creating sprawl as a byproduct. Li and Li (2019) observe the differences and socioeconomic drivers of urban sprawl in China. The study claims urban sprawl is driven by population density; GDP per capita; and industrial structure and has effecting ecoenvironmental and socioeconomic sustainability. The results revealed that regional distribution, urban size and hierarchy have different effects on urban sprawl in addition to the driving force assumed in the initial study.

Seemingly, urban sprawl persistently exists because of its driving force. For instance, Downs (1999) clearly described sprawl as a product of higher incomes, technological advances and also cost and convenience of travel to work. Higher incomes and earnings give freedom of choice to live further from busy, noisy cities. Technological advances, specifically in communication also allowed people to be working from home. Equally significant is when people have the convenience of travelling to work. The result is obvious: the problems of sprawl are innumerable.

\section{d. Defined by its pattern of growth}

Hayden (2004), defines sprawl as an extensive residential and commercial development resulting in a low-density, scattered, discontinuous, and car-dependent development that take place on the urban periphery while implying minimum control of planning and subdivisions. Apart from 
describing urban sprawl patterns, Hayden also emphasized the role of planning to control and restrain sprawl. The European Environment Agency (2006) also considered urban sprawl as a physically large development area with low density, under competitive conditions and predominantly encroaching on agricultural land. EEA also described sprawl as inefficiencies of urban growth and leapfrog development that created useless empty spaces. A study on European cities growth and change by Zambon and Salvati (2018) found that urban sprawl patterns in European cities are scattered and threaten their socio-environment function. Discontinued development decreased the efficiency of the provision of infrastructures and public service, thus created disruption in service provision and productivities.

Ewing (2008) refers to urban sprawl as undesirable land use patterns whether scattered, leapfrog, ribbon or continuous low-density development and at the same time has poor accessibility and lacks functional open spaces. The growth patterns are usually determined by the availability of adjacent land and variations of terrain. Accessibility has a direct correlation with the extent of the scatteredness of the pattern. The more scattered the pattern, the lower their accessibility. Low accessibility increased the travelling and transportation cost. Increased travelling pattern will result in decreased household disposable incomes. Increased transportation costs will result with the manufacturers and distributors shifting costs to consumers by increasing the price of goods. Both Ewing (2008) and EEA (2006) mentioned their concerned about empty spaces because of the tendency of unsustainable growth patterns caused by sprawl.

Downs (1999) mentions that urban sprawl patterns are happening across the USA and affecting federal policies such as open space initiatives. The study defines urban sprawl among others as low residential and commercial density, leapfrog and fragmented. The study presents the overall perspective of the complex urban sprawl subject by providing several evidences such as (i) sprawl neighborhoods suffer from poor quality public amenities e.g. public schools, public markets, parks; (ii) all major growth-related problems are regional in nature, not local; (iii) the cost of utilities and infrastructures are higher. Consequently, urban sprawl becomes difficult to alleviate by local authorities, gradually becomes low society districts, and higher assessment rates to compensate for expensive infrastructure and utilities. The evidence is comparable to a study on the impact of land finance on urban sprawl by Liu et al. (2018). The study defined urban sprawl in multiple forms: leapfrogged, low density residential and discontinuous development. The study concluded that local authorities face difficult tasks to gain a budget surplus from sprawled property because of poor public amenities and expensive infrastructures.

\section{e. Defined by its expansive character and excessive growth}

Since the US experienced urban sprawl from as early as the end of World War II, and having the peak of the issues in 1960s, Sinclair (1967) examined agricultural patterns near to industrialized areas and its relation to transportation cost. The study believes urban sprawl is associated with urban expansion at the cost of decreases in agricultural land as industrialization intensifies. However, Brueckner and Fansler (1983) provide a view on the urban economic aspect; justified urban sprawl and its spatial size is determined strictly by supply and demand which precisely allocates land for urban and agricultural purposes.

Lowry (1988) also looked at how urban sprawl effects transportation costs and the costs of compatibly configured land uses. The study defines urban sprawl as an expansion of urban areas to a sprawling low-density rural environ, referring to the urbanization trend in the USA in the 1960 s to 1980 s. The study has attempted to quantify the expense of movement of goods and people 
including work trip length and social and recreational travel, which concluded as highly impacted by the spatial organization and the transportation system.

Salvia et al. (2019) argues urban sprawl was formed because of residential overcrowding and increased population in the city center, resulting in an escalation of development to the outward urban fringe. However, the study indicated concern that urban jobs are still concentrated in the city center, thus the journey to work contributes to environmental consequences. Salvia et al. also alleged that the trend in countries with recently rising economies such as China, have the highest occurrence of urban sprawl. Aurambout et al. (2018) applied the Averaged Concentric Weighted Urban Proliferation index (ACWUP) and insisted that urban sprawl is a growth that extended once the urban center becomes tremendously crowded. They explained how changes in density and the proportion of development gradually lowers as it occurs further away from an urban center.

Likewise, Guite (2019) holds a similar view where the study defines urban sprawl as an expansion of urban margin and space functionality changes. The functionality change is also explained by Veneri (2018) who studied urban structure and urban population effected by sprawl where low-density growth takes place outside existing cores creating new centralities. These new centralities serve different firms and different socioeconomic groups thus creating different functionalities. Feng and $\mathrm{Li}$ (2013) look for an alternative strategy to achieve sustainable development in Beijing, Shanghai and Guangzhou. Feng and $\mathrm{Li}$ suggested that spatial reorganization and functional change is caused by de-densification and expansion of urban areas.

\section{f. Defined by its consequences to socio-environment}

Urban sprawl is deemed to be linked with environmental consequences. Thus, many definitions are comprised of the destructive characteristics to the environment and graphically provide a message of deterrence. According to Burchell et al. (1998), urban sprawl is associated with low accessibility, a prolonged journey to work in terms of time and distance which eventually make private transportation the only feasible option and inevitably increase carbon release. Burchell et al., examined urban sprawl all over the US and more than 600 counties were found to have sprawl. Thus, cumulative carbon release is significantly immense. Richardson and Bae (2005), defines urban sprawl as developing and building (urban built up) in sensitive areas which cause loss of forested land and harming to environmentally fragile areas. The study further explained that higher population incomes exhibited changes in preferences over types of neighborhoods, which lead to suburban and low-density residences that encroach on forest lands.

Ewing et al. (1997), Burchell et al. (1998) and Downs (1999), define urban sprawl with a multidimensional socio-environmental deprivation such as lack of scale economies, which decreased the suburban's standard of public services and declines the economic functionality of core urban areas, promote private transportation that produced a higher carbon footprint, scattered and fragmented urban encroachment of rural areas that caused irreversible damage to ecosystem. Wolff et al., (2018) conducted a quantitative study for a European spatial model and highlighted the ecosystem disturbance and decreased quality of air and health when defining urban sprawl. Viana et al., (2019) used a dynamic measure of remote sensing to perform urban sprawl analysis and the result is the region of interest suffered in terms of land, water, air, and health. Kovács et al. (2019) assess urban the expansion of post-socialism Budapest and found that urban sprawl has adverse consequences on the population socially, economically and environmentally. In similar 
tone, $\mathrm{Li}$ and $\mathrm{Li}$ (2019), Nope et al., (2020) and Zambon and Salvati (2018) discovered the same polarization and implication although they have distinct urban models.

To conclude, these definitions reflect their multidimensional nature and main differences from other forms or urban development. Furthermore, functional definition is provided in which its various intrinsic characteristics are differentiated contextually and are extricated from one to another. The first definition shows an immediate correspondence to principle governing action or procedure. The second urban sprawl definition looks at generic design or aesthetic measures. The third definition highlights what prompted urban sprawl. The fourth describes the unpredictable pattern of development. Next, the definition by its expansive character means the spatial reorganization and functionality change of an area. The last definition examines the effects and consequences to the socio-environment.

\section{The driving force of urban sprawl}

The state of urban sprawl is exceedingly varied and it has a different order in every city, state or continent. Thus, the forces, pressures and dynamics of urban sprawl are certainly diversified. Derived from previous academic literature, the driving forces of urban sprawl are presented into its urban properties: socioeconomic, institutional, demographic, market, and technological, as suggested in Figure 1.

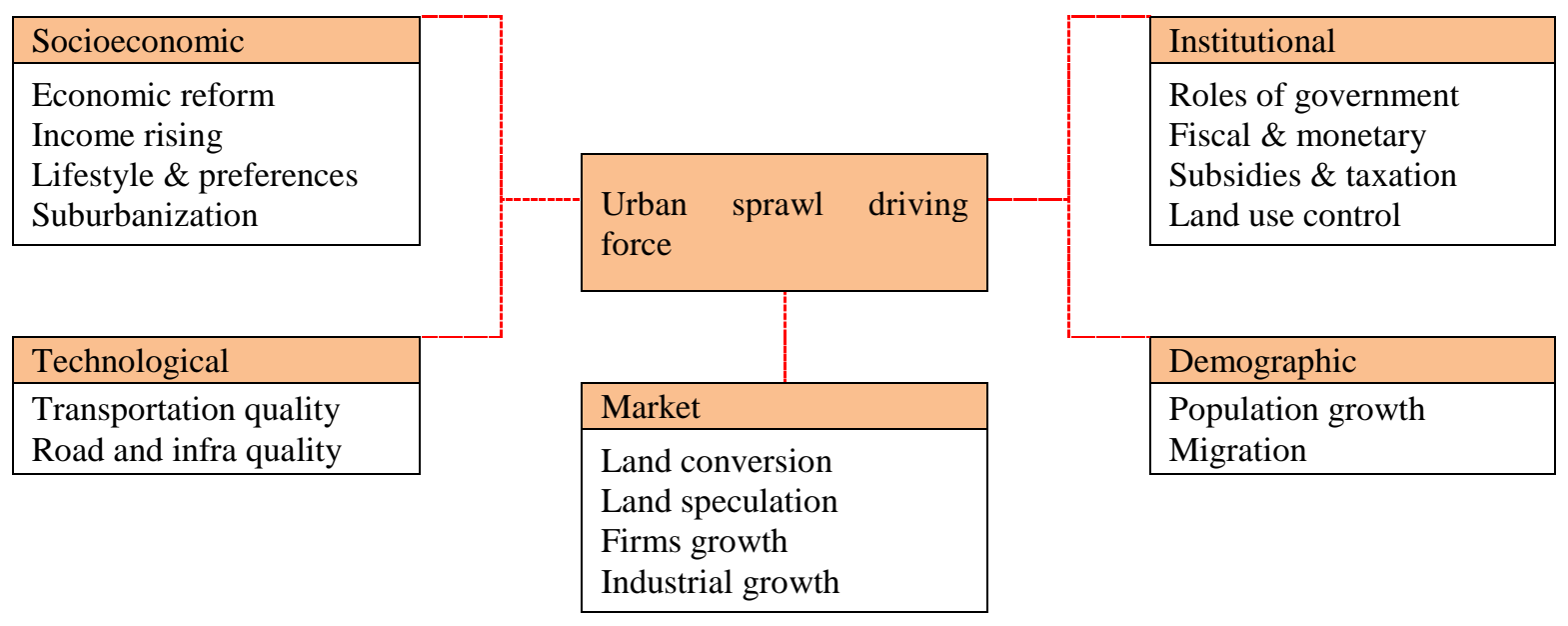

Figure 1. Revised urban sprawl driving force

\section{a. Socioeconomic}

Socioeconomic factors that drove urban sprawl include economic reform, increased household income, lifestyle and preferences, and suburbanization. Li and Li (2019) explain how national increment in household income drove urban sprawl by having more expensive low density suburban properties and higher standard of living. Eventually, rural and agricultural land cannot compete with real estate developer and this determine the spatial size and expansion of urban sprawl. Bhatta (2010), in her research finds that lifestyle and preference for suburban living are part of the aspects that contribute to urban sprawl. Boitie (2018) diagnosed the benefits of implementing an employee commuter-benefits program as compensation to their spatial cost. Employees who received commuter-benefit would prefer suburban living although they needed to 
commute on longer daily trips. Barnes et al. (2001) added that the daytime city population is full of white-collar workers and other professionals that are willing to commute to the suburbs on a daily basis. Some of them also prefer larger living spaces which is something difficult to hold in urban centers. Consequently, sub-factors such as increased household incomes, lifestyle and preference of white-collar workers and other professionals are dynamic and have reciprocally contributed to suburbanization.

\section{b. Institutional}

Politics and government institutionalization play major roles in the resource distribution and growth of cities. Public policy and federal government policy on taxes has a significant influence on urban sprawl (Zhang, 2000). Institutional roles, specifically government policies, have an enormous impact on urban sprawl compared to economic growth alone (Bart, 2010). National institutions that embrace long-term sustainable policies to contain and mitigate 'bad growth' have better chances to combat sprawl. A cross-national approach with continuous support from metropolitan governances that incorporate localized decision making made more of a difference (Sellers, 2002). Roles of government institutions with all-around governance can mobilize the local initiatives and make effective policies to curb sprawl. With a multi-role played by government institutions, urbanization and land use change evolve much faster than market speculation.

Fiscal policies on the other hand are heavily influenced by development density and distance from urban center (Pendall, 1999). The argument is, with fiscal policies, urban authority has the command either to provide or to transfer the infrastructures and utilities costs onto new growth. Some urban authorities give incentives such as tax relief for higher density and wider range of mixed-use development patterns. Ehrlich et al. (2018) also indicated that apart from fiscal policies, land use control policies also grasped the ability for urban authority to set an ideal density, type, size and location of residences where eventually it would cause a less sprawling pattern. Thus, the absence of land use control such as urban growth boundaries have significant spatial effects on urban sprawl because it has led to displaced growth for outlying areas and the encouragement of infill.

\section{c. Demographic}

Demographic factors, particularly in population growth and migration, have been recognized as one of the key factors of urban sprawl (Sudhira et al., 2003). As urban population expand, cities must grow spatially to accommodate more people. In addition, large migrations of rural populations, particularly labor, are attracted to urban life thus increasing urban population, although it is difficult to predict percentages (Fang \& Pal, 2016). Nevertheless, unsustainable urban growth occurs when the spatial growth exceeds urban population growth. This 'bad growth' tasks urban authorities to develop ever more elaborate systems for infrastructures, utilities and other public facilities (Pendall, 1999). Hence, rapid population growth not only turn out to be the main component of sprawl but is also responsible for environmental change and resource depletion. Hosseini and Hajilou (2019) claims overpopulation can cause cities to suffer from quality reduction in public amenities, overcrowded services delivery, and a decreased quality of life. The consequences of overpopulation in cities create pressure on growing spatial expansion and urban sprawl. Omurakunova et al. (2020) examined the impact of rural-urban and international 
migration to highly urbanized cities and finds out that cities unable to tolerate resource depletion - the only way to recover is to expand.

\section{d. Market}

Market forces have a great influence on land conversion, where rural agricultural productive land is not able to compete with rapid urban growth (Zhang, 2000). Zhang firmly believed that land is a primary economic element and a valuable commodity in urbanization, which is the reason for speculation and land conversion to urban use is much faster than the increase of urban population. These disproportional land conversions cause low-density and scattered development - two main growth patterns of urban sprawl. From the demand side, when demand for new urban land uses is high, not only is more land needed, but the profitability of land conversion is greater - thus land speculation occurs (Clawson, 1962). Clawson also suggest that the effect of land speculation in rapid urban growth is larger vacant leapfrog areas - a type of sprawl growth pattern. Fang and Pal (2016) explained how China's rapid economic transformation has resulted in significant urban sprawl in the past twenty years. The growth pattern of urban sprawl in China seems different because it features extremely rapid rates of land conversion and a tendency towards fragmentation and dispersion at the same time. This extreme urbanization rate is also contributed to massive land conversion from rural agricultural lands to economically-driven urban fringe lands.

\section{e. Technological}

New technologies revolutionize the ways people communicate, travel (use transportation) and choose to live. Transportation improvement have enabled people to travel further (daily commute) and have expanded choices for living outside the urban peripheries (Nechyba \& Walsh, 2004). Inadvertently, by creating these choices, people have higher levels of housing and land consumption for most households. However, Nechyba and Walsh (2004) concluded that it comes with associated costs: congestion, pollution, encroachment, inadequate provision of amenities, lacks open space, and sprawl. Brueckner (2000) shares the same view: with improved roads and other modes of transportation, more people choose to live in suburban neighborhoods which eventually leads to sprawl. However, there is no current result within articles that back the above statement, which means the technological factor is no longer a strong driving force for urban sprawl.

The findings show that the most often stated urban sprawl driving force is the absence or inclination of a spatial or land use policy. Little attention was given to spatial policies and planning in urban management despite the widely accepted premise that planning effects urban growth and sprawl. The second most stated urban sprawl driving force is population growth. Managing local population growth has drawn attention to the intensity of land use as measured by gross residential density because greater population density lowers the costs of providing public services and lower population density increases it. To mitigate, there is a need to strengthen development plans and urban growth boundaries by (i) the means to implement the plans with sustainable development (ii) to address the role of other driving forces influencing the implementation. 


\section{Conclusion}

The purpose of this study has been to re-examine the definitions and the driving forces of urban sprawl. In particular the study has composed six definitions of urban sprawl which were thoroughly constructed to include physical, morphological, causal, preferential, social and environmental aspects of urban environment. The study established the following premises on urban sprawl: (1) the absence of development control (2) the non-compliance to urban development policy; (3) the consequences of land speculation; (4) decreased the efficiency of the provision of infrastructures and public service; (5) increased the cost of transportation and compatibly configured land use; and (6) losses of agricultural, forest and sensitively fragile land. This has been linked with the fundamental problem where certain policies formulated without informed knowledge would have gratified urban sprawl.

The driving force of urban sprawl has been revised to delineate distinctions between these aspects: socioeconomic, institutional, demographic, market, and technological. The main findings are the following: (1) increment in GDP per capita drove urban sprawl; (2) fiscal policies can heavily influence urban growth's size and densities; (3) reduced quality of public amenities, service delivery and quality of life; (4) market forces have a great influence on land conversion; (5) transportation quality has enabled people to daily commute and living away from cities. Uninformed decisions and the least conceptual understanding have had negative impacts on the spatial planning of urban growth. While there is still plenty of evidence required to support some of these findings, this study has provided new insights and would amplify further research on urban sprawl characteristics and consequences.

\section{References}

Aurambout, J.-P., Barranco, R., \& Lavalle, C. (2018). Towards a Simpler Characterization of Urban Sprawl across Urban Areas in Europe. Land, 7(1), 33.

Bahl, R. W. (1968). A land speculation model: the role of the property tax as a constraint to urban sprawl. Regional Science, 8(2), 199-208.

Barnes, K. B., III, J. M. M., Roberge, M. C., \& Lowe, S. (2001). Sprawl Development. Its Patterns, Consequences and Measurement. A white paper. Towson University Maryland.

Bart, I. L. (2010). Urban sprawl and climate change: A statistical exploration of cause and effect with policy option for the EU. Land Use Policy, 27(2), 283-292.

Benites-Gambirazio, E. (2017). The social logic of urban sprawl: Arizona cities under enviromental pressure. In F. Poupeau, H. Gupta, A. Serrat-Capdevila, M. A. Sans-Fuentes, S. Harris \& L. G. Hayde (Eds.), Water Bankcruptcy in the Land of Plenty: CRC Press,.

Bhatta, B. (2010). Analysis of Urban Growth and Sprawl from Remote Sensing Data. Kolkata India: Springer Heidelberg Dordrecht

Boitie, V. (2018). The role of labor market structure in urban sprawl. Regional Science and Urban Economics, 73, 83-98.

Brueckner, J. K. (2000). Urban sprawl: diagnosis and remedies. International Regional Science Review, 23(2), 160-171.

Brueckner, J. K., \& Fansler, D. E. (1983). The economics of urban sprawl: theory and evidence on the spatial size of cities. Review of Economics and Statistics, 65(3), 479-482. 
Bruegmann, R. (2015). Urban sprawl. International Encyclopedia of the Social and Behavioral Sciences, 2(24), 934-939.

Burchell, R. W., Shad, N. A., Listokin, D., \& Phillips, H. (1998). The Cost of Sprawl - Revisited. Transit Cooperative Research Program, Report 39. Washington D.C.: National Academy Press.

Clawson, M. (1962). Urban Sprawl and Speculation in Suburban Land. Land Economics, 99-111.

Dibble, J., Prelorendjos, A., \& Romice, O. (2019). On the origin of spaces: Morphometric foundations of urban form evolution. Environment and Planning B-Urban Analytics And City Science, 46(4), 707-730.

Dowling, T. J. (2000). Reflections of urban sprawl, smart growth and Fifth Amendment. University of Pennsylvania Law Review, 148(3), 873-887.

Downs, A. (1999). Some realities about sprawl and urban decline. Housing policy debate, 10, 955973.

Ehrlich, M. V., Hilber, C. A. L., \& Schöni, O. (2018). Institutional settings and urban sprawl: Evidence from Europe. Journal of Housing Economics, 42, 4-18.

Europe Environmental Agency (EEA) (2006). Urban sprawl in Europe, the ignored challenge 10 (pp. 56). Copenhagen: European Commission Joint Research Center.

Ewing, R. H. (2008). Characteristics, Causes, and Effects of Sprawl: A Literature Review. In J. M. Marzluff (Ed.), Urban Ecology: An International Perspective on the Interaction Between Human and Nature (pp. 519-536). New York: Springer Science.

Ewing, R. H., Bartholomew, K., Winkelman, S., Walters, J., Chen, D., McCann, B., \& Goldberg, D. (1997). Growing cooler: The evidence on urban development and climate change: Urban Land Institute.

Fang, Y., \& Pal, A. (2016). Drivers of urban sprawl in urbanizing China - a political ecology analysis. Environment \& Urbanization, 28(2), 599-616.

Feng, S., \& Li, Q. (2013). Car Ownership Control in Chinese Mega Cities: Shanghai, Beijing and Guangzhou. Journeys (LTA Academy Singapore).

Feng, Y., Wang, X., Du, W., Liu, J., \& Li, Y. (2019). Spatiotemporal characteristics and driving forces of urban sprawl in China during 2003-2017. Journal of Cleaner Production, 241, 118061.

Franklin, R. S., \& Plane, D. A. (2019). The View from Over the Hill: Regional Research in a PostDemographic Transition World. In R. J. a. P. Schaeffer (Ed.), Regional Research Frontiers - Vol. 1 Innovations, Regional Growth and Migration. West Virginia: Springer International Publishing.

Fulton, W. (1996). The new urbansim. Cambridge MA Lincoln Institute of Land Policy.

Galster, G., Hanson, R., Ratcliffe, M. R., Wolman, H., Coleman, S., \& Freihage, J. (2001). wresting sprawl to the ground: defining and measuring an elusive concept. Housing policy debate, 12(4), 681-717.

Gordon, P., \& Richardson, H. W. (1997). Are compact cities a desirable planning goal. Journal of The American Planning Association, 63, 95-106.

Guan, D., He, X., He, C., Cheng, L., \& Qu, S. (2020). Does the urban sprawl matter in Yangtze River Economic Belt, China? An integrated analysis with urban sprawl index and one scenario analysis model. Cities, 99.

Guite, L. T. S. (2019). Assessment of urban sprawl in Bathinda city, India. Journal of Urban Management, 8(2), 195-205. 
Habibi, S., \& Asadi, N. (2011). Causes, results and methods of controlling urban sprawl. 2011 International Conference on Green Buildings and Sustainable Cities. Procedia Engineering, 21(2011), 133-141.

Hayden, D. (2004). A field guide to sprawl. New York: W. W. Norton of Company.

Horn, A. (2014). Urban Growth Management Best Practices: Towards Implications for the Developing World. International Planning Studies, 20(1-2), 131-145.

Hosseini, S. H., \& Hajilou, M. (2019). Drivers of urban sprawl in urban areas of Iran. Regional Science, 98(2), 1137-1158.

Kovács, Z., Farkas, Z. J., Egedy, T., Kondor, A. C., Szabó, B., Lennert, J., . . Kohán, B. (2019). Urban sprawl and land conversion in post-socialist cities: The case of metropolitan Budapest. Cities, 92.

Li, G., \& Li, F. (2019). Urban sprawl in China: Differences and socioeconomic drivers. Science of The Total Environment, 673, 367-377.

Liu, Y., Fan, P., Yue, W., \& Son, Y. (2018). Impacts of land finance on urban sprawl in China: The case of Chongqing. Land Use Policy 72, 420-432.

Lowry, I. S. (1988). Planning for urban sprawl Transportation Research Board Special Report (Vol. 220, pp. 275-312). Washington DC: Transportation Research Board.

Mills, D. E. (1981). Growth, speculation and sprawl in a monocentric city. Journal of Urban Economics 10(2), 201-226.

Nechyba, T. J., \& Walsh, R. P. (2004). Urban Sprawl. Journal of Economic Perspectives, 18(4), 177-200.

Nelson, A. C., \& Duncan, J. B. (1995). Growth Management Principles and Practices. Chicago: Planners Press.

Nope, K. B. N., Suthanaya, P. A., Wedagama, D. M. P., \& Astana, I. N. Y. (2020). The Jakarta TOD Model Application for Typology of Middle Cities (Applied Research Design in Kupang City). Geographia Technica, 15, 103-112.

Omurakunova, G., Bao, A., \& Xu, W. (2020). Expansion of Impervious Surfaces and Their Driving Forces in Highly Urbanized Cities in Kyrgyzstan. International Journal of Environmental Research and Public Health, 17(1), 362.

Peiser, R. B. (1984). Does it pay to plan suburban growth. Journal of The American Planning Association, 50(4), 419-433.

Peiser, R. B. (2001). Decomposing Urban Sprawl. Town Planning Review, 72(3), 275-298.

Pendall, R. (1999). Do land use controls cause sprawl. Environment and Planning B: Planning and Design, 26, 555-571.

Richardson, H. W., \& Bae, C.-H. C. (2005). Urban Sprawl in Western Europe and the United States Journal of Housing and the Built Environment, 20(4), 453-456.

Salvia, R., Serra, P., \& Zambon, I. (2019). In-Between Sprawl and Neo-Rurality: Sparse Settlements and the Evolution of Socio-Demographic Local Context in a Mediterranean Region. Sustainability, 10(10), 3670.

Sellers, J. M. (2002). Federalism and metropolitan governance in cross national perspective: the case of urban sprawl. Environment and Planning C, 20, 95-112.

Sinclair, R. (1967). Von Thunen and urban sprawl. Paper presented at the Annual of the Association of American Geographer

Sudhira, H., Ramachandra, T., \& Jagadish, K. (2003). Urban sprawl pattern recoqnition and modelling using GIS. Paper presented at the Map India Conference 2003. 
Veneri, P. (2018). Urban spatial structure in OECD cities: Is urban population decentralising or clustering? Regional Science, 97(4), 1355.

Viana, C. M., Oliveira, S., Oliveira, S. C., \& Rocha, J. (2019). Land Use/Land Cover Change Detection and Urban Sprawl Analysis. In Hamid Reza Pourghasemi \& Candan Gokceoglu (Eds.), Spatial Modeling in GIS and R for Earth and Environmental Sciences. Amsterdam: Elsevier Inc.

Wolff, M., Haase, D., \& Haase, A. (2018). Compact or spread? A quantitative spatial model of urban areas in Europe since 1990. PLOS One, 13(2).

Wu, J. J. (2006). Environmental amenities, urban sprawl, and community characteristics. Environmental Economics and Management, 52(2), 527-547.

Yu, Z. (2013). Urban Sprawl. The Encyclopedia of Human Migration. John Wiley \& Sons, Inc.

Zambon, I., \& Salvati, L. (2018). Demographic dynamics, economic expansion and settlement dispersion in Southern Europe: contrasting patterns of growth and change in three metropolitan regions. Management Research and Practice, Research Centre in Public Administration and Public Services, Bucharest, Romania, 10(2), 41-62.

Zhang, T. (2000). Land market forces and government's role in sprawl: The case of China. Cities, 17(2), 123-135. 